\title{
MODELLING OF INVESTMENT PROCESSES IN THE SPHERE OF SOCIAL HOUSE BUILDING
}

\author{
Larisa Seliutina, ${ }^{1}$ Marina Egorova, ${ }^{2}$ Kseniia Bulgakova ${ }^{3}$
}

\begin{abstract}
The problem of not enough public housing for low-income citizens is very urgent in the entire world. This article is dedicated to the topical question; how do we select optimal investment projects and implement successful investment programs to fund public housing projects better. We have formulated basic principles for the formation of an optimal portfolio to use as a standard for investment programs for public housing construction projects. As selection criteria, instead of profitability and risk offered in classical portfolio theory to which private investors are paying attention, we propose the use of social satisfaction survey results and amount of available funding to determine the effectiveness of the programs. We have developed several mathematical models that help aid in the selection of investment projects based on these new requirements. The application of these models in the selected projects selection within the framework of investment programs of public housing construction will allow the most effective use of funds directed to the development of the public housing.
\end{abstract}

JEL Classification Numbers: R39; DOI: http://dx.doi.org/10.12955/cbup.v5.904

UDC Classification: 332.05

Keywords: Construction, housing, investment, finance

\section{Introduction}

Regardless of the form of government, comfortable housing is always high on the hierarchy of human needs (Heijden, Haffner, \& Hoekstra, 2006). Originally, the role of the social housing sector was to provide universal access to adequate housing (Zhuk, 2012). Today, a majority of the population buy and rent housing based on a market that is a product of the state's interaction with vulnerable citizens.

Improving the interaction between all participants of public housing investment has occurred since the beginning of XVII century. This sphere differs in complexity and versatility. Therefore, it requires a scientific approach to its investigation (Selyutina \& Bulgakova, 2014). Without competent control of investments, it is impossible to implement the programs of modern housing, form a favorable investment climate in the region, and carry out structural reforms and responsible housing policy (Berens \& Havranek, 2007).

The principle of competent control also works in the opposite direction to increase of people's quality of life, which is impossible without economic growth. Therefore, during the development of the programs for social housing one should not forget about economic efficiency.

\section{Theoretical Frameworks}

Financial theory became a science in the early to mid-20th century when the Fisher income discounting technique (2003) was used for the first time. In this economist's opinion, to correctly assess future income in the present, one needs to relate the cost of services with capital cost. An evaluation of the main (capital) assets was central in the works of Williams (1995), a recognized investor in the United States of America.

Economists have offered several approaches to evaluate assets to allow controlling investment portfolios. However, all pre-war works were created with a hypothesis about the definiteness of conditions of financial solutions. Therefore, in financial analysis, elementary financial mathematics was used.

The work of Knight (1921) in 'Risk, Uncertainty and Profit' contains the first quality analysis of the probability-theoretic mathematical methods of risk events influence. In addition, the recommended set of projects was called investment programs. Some scientists reason that these two concepts are equal. Some economists complete the concept of the investment program, opening it as an element of the investment strategy of the state. For example, Tyrtyshov (2004) emphasizes that the program is a commitment that can create and mobilize resources for its implementation.

\footnotetext{
${ }^{1}$ Petersburg State Transport University Emperor Alexander I Saint-Petersburg, Russia, ya.slarisa@ya.ru

${ }^{2}$ The Bonch-Bruevich Saint - Petersburg State University of Telecommunications, Saint-Petersburg, Russia, egorovamak@ya.ru

${ }^{3}$ Saint-Petersburg State University of Economics, Saint-Petersburg, Russia, pierott_89@mail.ru
} 
Possibly, the term 'investment program' has a wider meaning than the notion of 'investment portfolio' used more so today, but these terms frequently coincide in practice. Therefore, within the framework of this current research, the two terms are considered identical.

Modern investment theory is closely connected with Markowitz (1959; 1987). His models allowed investment projects that were selected because of risk and profitability to be translated into mathematical language. The main results of scientists-economists, acknowledged in the 20th century, are focused on the works of Markowitz, the essence of which being that a project's portfolio is created using the relation of risk-profitability or certain combinations of risk and profitability (Markowitz, 1959 ; 1987).

To maximize profit and minimize risks, investors deal not only with one asset but allocate capital to different projects. A combination of projects creates new investment qualities and perspectives. Evaluation of separate assets and their portfolios. Modern investment theory considers two characteristics: risk and profitability, which are assessed quantitatively to allow the investor to form an optimal investment portfolio. The theory of 'Efficient set of portfolios' remains a summit of classic economic theory (Merton, 1969). As stated by Investopedia (2017), "Portfolio variance is calculated by multiplying the squared weight of each security by its corresponding variance and adding two times the weighted average weight multiplied by the covariance of all individual security pairs."

\section{Data and Methodology}

Main Argument

Based on the assumption that, for the solution of the portfolio formation, the method and order of steps can be determined explicitly, a model is formed under a determined set of characteristics in various investment projects $(\operatorname{Pr})$, where:

$$
\operatorname{Pr}=\operatorname{Pr}_{1}, \operatorname{Pr}_{2}, \operatorname{Pr}_{3} \ldots \operatorname{Pr}_{n}
$$

Where the program of social house building ( $\mathrm{SPr}$ ) is derived from the suggested investment-building projects, the program was described as a subset of investment projects from the set, as follows:

$$
\text { SPr } \subset \operatorname{Pr}
$$

In the investment program, the characteristic vector, $\mathrm{X}(\mathrm{X} 1, \mathrm{X} 2, \ldots, \mathrm{Xn})$ was used to define the structure of the program. In this case, $\mathrm{X}_{i}$ was ' 1 ' when the $i$-th project $\left(\operatorname{Pr}_{i}\right)$ was included in the program and ' 0 ' when not.

For selecting optimal projects within the framework of socially-affordable housing, the new representation was social satisfaction $\left(\mathrm{SS}_{i}\right)$ by the $i$-th investment project $(\mathrm{Pr})$.

This representation can be interpreted as direct, for example, by the number of citizens having improved housing conditions, as well as indirect, for example, the decrease of tension in society and the formation of new working places. Social satisfaction was evaluated subjectively by each expert based on hypotheses and formulations of this study.

All social investment programs balance the contradictive conditions of limited financing and social effect requirements.

The coefficient of social satisfaction, SS, was determined by experts by estimating the following local social satisfaction factors:

- The number of families who improved their living conditions;

- The features of social adaptation of citizens;

- The load on the existing infrastructure in the area; and

- Possibilities for further construction.

Representations of a social effect and, consequently, social satisfaction were subjective, and every expert calculated these independently.

Representations of social satisfaction were considered deterministic variables or random variables defined on the following probability space:

$$
<S, B, P>
$$

where 
$\mathrm{S}=$ sample space of all possible outcomes;

$\mathrm{B}=$ Borel algebra of events on the sample space $\mathrm{S}$, collection of all events we consider; and

$\mathrm{P}=$ probability measure defined for every event $\mathrm{A} \in \mathrm{B} ; \mathrm{P}(\mathrm{S})=1$. A is the coefficient of investor's risk sensitivity.

The random variable, $\mathrm{SS}_{i}$, of social satisfaction from every investment project available for evaluation was based on:

where

$$
r_{i}=\left(r_{i 1}, r_{i 2}, \ldots, r_{i k}\right)
$$

$\mathrm{k}=$ sample size of expert values, and

$\mathrm{r}_{\mathrm{ik}}=$ value $\geq 2$ derived by experts from the set of projects, characterized by a distribution function, $\mathrm{F}_{i}(\mathrm{t})$.

The study considered $\mathrm{F}_{i 0}$ as a class of all possible distribution functions, $\mathrm{F}_{i}(\mathrm{t})$, from which a random sample, $\mathrm{r}_{i}$ (return of $i$-th asset), could be drawn.

Another criterion in selecting an investment project was the amount of financing for an investment program $(V)$.

Based on the above-mentioned criteria, a mathematical model of the investment project was built for the program of social housing.

The characteristics and conditions of investment projects were defined, a task rarely performed in practice. Hence, every investment project was characterized by the following descriptions:

- $S S$, a coefficient of social satisfaction of the project; and

- $V$, the required amount of financial means calculated for the project.

The resulting models allowed one to determine optimal social projects with maximal social effect under a budget constraint.

Where $V$ suggested financing of the program during a certain period, it was assumed that the total demand for financing should not exceed the possible financing during that fixed period. As a result, the social satisfaction of components of the program, consisting of various investment projects, were determined as:

$$
S S=\sum_{i=1}^{n} S S_{i} X_{i}
$$

An investment program of social housing can be constructed using different approaches depending on the choice of criteria and constraints. Based on two key factors, two main models for forming a social housing program were proposed.

Model 1

This model was based on maximizing social significance under limited financing needs. From the set of investment projects, a subset of projects was chosen to form programs that satisfy the constraint of limited financing. Then, among those programs, the program with the maximal social significance was chosen. It was necessary to use a set of vectors $\mathrm{X}=(\mathrm{X} 1, \mathrm{X} 2, \ldots, \mathrm{Xn})$, where each $\mathrm{X}_{i}$ had a value of ' 0 ' or ' 1 ' and

$$
\left\{\begin{array}{c}
\sum_{i=1}^{n} X_{i} S S_{i} \rightarrow \max \\
\sum_{i=1}^{n} X_{i} V_{i} \leq V_{0}
\end{array}\right.
$$

Model 2

This model was based on minimizing finances based on the required level of social satisfaction. In this case, from the full set, the only investment projects selected to form the programs were those that satisfied constraints, in particular, those with the level of satisfaction at least or lower than $\mathrm{SS}_{0}$.

Then, among those programs one with the minimally expected financing was identified. It involved a set of vectors $\mathrm{X}=(\mathrm{X} 1, \mathrm{X} 2, \ldots, \mathrm{Xn})$, where each $\mathrm{X}_{i}$ had a value of ' 0 ' or ' 1 ' and

$$
\left\{\begin{array}{l}
\sum_{\mathrm{i}=1}^{\mathrm{n}} \mathrm{X}_{\mathrm{i}} \mathrm{V}_{\mathrm{i}} \rightarrow \min \\
\sum_{\mathrm{i}=1}^{\mathrm{n}} \mathrm{X}_{\mathrm{i}} \mathrm{SS}_{\mathrm{i}} \leq \mathrm{S}_{0}
\end{array}\right.
$$

The value for $\mathrm{SS}_{0}$ represented the required level of social satisfaction of project components. The solution of the program formation resulted with the help of the typical optimization programs. 
A mathematical expectation of return in classic theory of investment was an expected return and the variance of return represented the expected risks of investors or risks in general. In the suggested models, the mathematical expectation of significance for projects and programs defined the expected social satisfaction and the variance of significance the risk of investment program or risk in general (Modigliani, 1949).

In practice, investment projects were usually characterized not only by the determined demand in financing but by the random subjective value of social satisfaction, since it depended to a large extent on the experts' opinion.

The value representing the sample of expert values was $k \geq 2$, and some general population were characterized by the distribution function $\mathrm{F}_{i}(\mathrm{t})$. In this, $\mathrm{F}_{0 \mathrm{i}}$ is a class of possible distribution functions $\mathrm{F}_{i}(\mathrm{t})$, from which sampling $\mathrm{r}_{i}$ can be derived as:

$$
r_{i}=\left(r_{i 1}, r_{i 2}, \ldots r_{i k}\right)
$$

The evaluation of the mathematical expectation and dispersion of characteristics was applied to social satisfaction as follows:

$$
\begin{aligned}
m_{i} & =\frac{1}{k} \sum_{i=1}^{k} r_{i k} \\
D_{i} & =\frac{1}{k} \sum_{i=1}^{k}\left(m_{i}-r_{i k}\right)^{2} \\
\sigma_{i} & =\sqrt{D_{i}}
\end{aligned}
$$

where

$\mathrm{m}_{i}=$ a mathematical expectation of social satisfaction of $i$-th investment project;

$\mathrm{D}_{i}=$ variance of social satisfaction of members of $i$-th investment project;

$\sigma_{i}=$ standard deviation of social satisfaction of the members of the $i$-th investment project.

The mathematical expectation of social satisfaction of investment program was determined by the formula:

$$
\mathrm{R}=\sum_{\mathrm{i}=1}^{\mathrm{n}} \mathrm{X}_{\mathrm{i}}^{2} \mathrm{D}_{\mathrm{i}}
$$

For the case of dependent results of satisfaction regarding investment projects, the variance of socially oriented investment program was determined as:

$$
\mathrm{D}=\sum_{\mathrm{i}=1}^{\mathrm{n}} \sum_{\mathrm{j}=1}^{\mathrm{m}} \mathrm{X}_{\mathrm{i}} \mathrm{X}_{\mathrm{j}} \mathrm{D}_{\mathrm{ij}}
$$

where

$\mathrm{D}=$ the covariance between returns of two investment projects in the case of $i=j$ being a variance.

It was assumed that $\mathrm{V}_{0}$ was the potential amount for financing the socially oriented program during a certain period. Consequently, the total demand for financing of the socially oriented investment program could not exceed this potential amount.

Socially oriented investment programs can be formed and implemented within a day or in a few periods, depending on the established criteria. From this study, under random characteristics of social satisfaction, the following models of formation of optimal socially oriented projects were developed.

The first model of program formation is based on the maximization of expected social satisfaction of investment program under acceptable risk and financing limitations. Then, the economic and mathematical model will be formulated in the following way: it is necessary to choose from the given set of projects such a subset that form programs which satisfy the constraints of limited financing and limited risks. From those programs from the 'feasible region' chose the one with the maximal expected social satisfaction. In other words, it is necessary to find such a set of vectors $X=(X 1, X 2$, $\ldots, X n)$, where every $X_{i}$ takes two possible values ( 0 and 1$)$ to meet the following constraints and among them chose the one which satisfies the maximization criterion:

$$
\left\{\begin{array}{c}
\sum_{\mathrm{i}=1}^{\mathrm{n}} \mathrm{X}_{\mathrm{i}} \mathrm{m}_{\mathrm{i}} \rightarrow \max \\
\sum_{\mathrm{i}=1}^{\mathrm{n}} \mathrm{X}_{\mathrm{i}} \mathrm{D}_{\mathrm{i}} \leq \mathrm{D}_{0} \\
\sum_{\mathrm{i}=1}^{\mathrm{n}} \mathrm{X}_{\mathrm{i}} \mathrm{V}_{\mathrm{i}} \leq \mathrm{V}_{\mathrm{o}}
\end{array}\right.
$$

where 


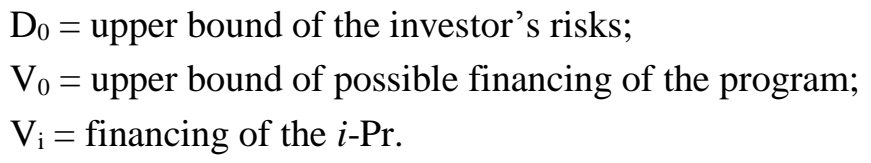

The model describes the optimization problem of finding the program, which gives maximal social satisfaction under the terms of limited risks, and limited financing. Its solution can be calculated with the help of typical optimization program.

The second model of program formation is based on the minimization of financing of the program under acceptable risk limitation and achievement of required level of social significance. Such conditions can be described by the following economic and mathematical model. From the given set of investment projects, it is necessary to choose such a subset of projects that form programs which fulfill the constraints. It means that the chosen programs do not need to exceed the maximally acceptable risk $\mathrm{D}_{0}$ and in the same time their expected social satisfaction should be at least as high as minimally acceptable level $\mathrm{SS}_{0}$. Those programs form a feasible set of the programs. Moreover, our task is to choose the one program from the feasible set with the minimal financing demands.

That is, the task is to find such a set of vectors $\mathrm{X}=(\mathrm{X} 1, \mathrm{X} 2, \ldots, \mathrm{Xn})$ to achieve for which constraints of achievement at least minimal expected significance of the program $\mathrm{SS}_{0}$ and not to exceed maximal acceptable risk $\mathrm{D}_{0}$ are mutually fulfilled. From the set of received programs choose the one with the minimal financing requirements. In mathematical language, this task can be described in the following way:

$$
\left\{\begin{array}{c}
\sum_{\mathrm{i}=1}^{\mathrm{n}} \mathrm{X}_{\mathrm{i}} \mathrm{V}_{\mathrm{i}} \rightarrow \min \\
\sum_{\mathrm{i}=1}^{\mathrm{n}} \mathrm{X}_{\mathrm{i}} \mathrm{D}_{\mathrm{i}} \leq \mathrm{D}_{0} \\
\sum_{\mathrm{i}=1}^{\mathrm{n}} \mathrm{X}_{\mathrm{i}} \mathrm{SS}_{\mathrm{i}} \leq \mathrm{SS}_{\mathrm{o}}
\end{array}\right.
$$

where

$\mathrm{SS}_{0}=$ minimal social significance, lower bound of the social significance to be reached;

$\mathrm{D}_{0}=$ upper bound of the investor's risks, this level of risks cannot be exceeded.

\section{Results and Discussion}

Thus, for selecting social housing investment projects, one can apply the following principles:

- Social significance. To form project portfolio, the authors suggest using new representations of social significance that are of importance of the project for society.

- a posteriori return. Evaluation of investment projects of social housing is secondary and can be carried out a posteriori.

- Collective decision. Decisions on investment to any project should be made together with experts and investor, using subjective judgments about their advisability. Experts' opinions and evaluations are considered as random values of some allocation.

- Adaptability. All chosen investment projects should react operatively to changes of external environment, and mainly to continue developing and realization in dynamically changing conditions of the external environment.

- Complexity. Investment program should be, first of all, oriented to complex socially-economic development of the region. Therefore, experts' decision on projects should be systemic and consistent.

- Consistency (balance of interests). All members of the expert group should serve to the achievement of common goals, and personal goals of each member should not cause contradictions between the links.

- Transparency. The procedure of projects selection, formation, realization, and evaluation of program should be maximally transparent and available to ensure awareness of all desiring investors about the possibility of participation in the program, changes in projects, their possible social significance, return and risks.

- Rationality. Investment budget should be rationally allocated to maximally and minimally effective projects.

- Professionalism. Only competent members should be attracted to investment projects, e.g., government employees, investors, facility managers, appraisers, and other interested persons. 
- Objective evaluation. There is a need for introducing a united system of monitoring and accounting that will help to evaluate social and economic effects of project realization maximally.

- Management resonance. The great value is assigned to identify investments and resonance in the system and maximizing economic and social effect.

\section{Conclusion}

The models produced in this study will help with forming an optimal portfolio of investment projects in the framework of limited budget and limited acceptable risks with maximization of social satisfaction. Consequently, to form an optimal package of projects with the minimal financing requirements will provide at least the required number of citizens with housing. Projects will form without exceeding acceptable risks. The key task for the realization of the social housing programs is an increase of regional quality of life from achieving the programs. As a result, more citizens will be provided with comfortable housing and thus, relations between society and state will potentially stabilize. With the most 'vulnerable' citizens protected social tension in society should automatically reduce (Selyutina, 2016).

\section{References}

Berens, B. \& Havranek, P.M. (1995). Guidance on evaluation of investment efficiency. Moscow: Infra-M , 235-238

Heijden H.M., Haffner M.E. \& Hoekstra J.S. (2006), Bridging the Gap Between Social and Market Rented Housing in Six European Countries.Delft: Delft University.

Knight, F.H. (1921). Risk, Uncertain and Profit. New York: Houghton Mifflin Publ.

Fisher P. (2003). Common stocks and uncommon profits. New Jersey: John Wiley and Sons. Inc. Publ.

Markowitz, H.M. (1959). Portfolio Selection: Efficient Diversification of Investments. New York: Jolin Wiley Publ. 135-145

Markowitz, H.M. (1987). Mean-Variance Analysis in Portfolio Choice and Capital. New York: Jolin Wiley Publ. 211-213

Merton, R.C. (1969) Lifetime portfolio selection under uncertainty: the continuous - time case. Review of Economic and Statistics, 51, 247-257.

Modigliani, F. (1949). Fluctuation in the Saving income ratio: a problem in economic forecasting. Studies in Income and Wealth. New York: NBER Publ., XI, 445.

Selyutina, L. \& Bulgakova, K (2014). Development of nonprofit housing as a method of forming an affordable and comfortable accommodation in Saint-Petersburg. Theory and practice of social development, 1, 374-376.

Selyutina, L. (2016). Formation of market offers in the field of construction and reconstruction of housing in Russia. Scientific results. Series: Technology, business and service. V. 2, No. 3, 44-56. DOI: 10.18413/2408-9346-2016-2-3-50-56 Tyirtyishov, Y.P. Problems of formation of affordable housing market in the Russian Federation. Construction Economy, 11, 3-38.

Williams, D.B. (1995). Trading chaos or profit maximization. Moscow: IR Analysis.

Zhuk, V.A. (2012). Regional housing policy in the development strategy of major cities. St. Petersburg: ROST.176-178.

Expected Return, Variance And Standard Deviation Of A Portfolio (2017). Retrieved from:

http://www.investopedia.com/walkthrough/corporate-finance/4/return-risk/expected-return.aspx 